\title{
Severe insulin resistance syndromes
}

\author{
Angeliki M. Angelidi, ${ }^{1}$ Andreas Filippaios, ${ }^{2}$ and Christos S. Mantzoros ${ }^{1,3}$ \\ 'Department of Medicine, Beth Israel Deaconess Medical Center, Harvard Medical School, Boston, Massachusetts, USA. Department of Medicine, Lowell General Hospital, Lowell, Massachusetts, USA. \\ ${ }^{3}$ Section of Endocrinology, Boston VA Healthcare System, Harvard Medical School, Boston, Massachusetts, USA.
}

\begin{abstract}
Severe insulin resistance syndromes are a heterogeneous group of rare disorders characterized by profound insulin resistance, substantial metabolic abnormalities, and a variety of clinical manifestations and complications. The etiology of these syndromes may be hereditary or acquired, due to defects in insulin potency and action, cellular responsiveness to insulin, and/or aberrations in adipose tissue function or development. Over the past decades, advances in medical technology, particularly in genomic technologies and genetic analyses, have provided insights into the underlying pathophysiological pathways and facilitated the more precise identification of several of these conditions. However, the exact cellular and molecular mechanisms of insulin resistance have not yet been fully elucidated for all syndromes. Moreover, in clinical practice, many of the syndromes are often misdiagnosed or underdiagnosed. The majority of these disorders associate with an increased risk of severe complications and mortality; thus, early identification and personalized clinical management are of the essence. This Review aims to categorize severe insulin resistance syndromes by disease process, including insulin receptor defects, signaling defects, and lipodystrophies. We also highlight several complex syndromes and emphasize the need to identify patients, investigate underlying disease mechanisms, and develop specific treatment regimens.
\end{abstract}

\section{Introduction}

This Review, inspired by the 100th anniversary of insulin's discovery, focuses on severe insulin resistance syndromes, which constitute only the tip of the iceberg of a wide variety of clinical disorders associated with various degrees of insulin resistance. Historically, the ability to measure insulin in the circulation in the 1960 s led to the realization that many subjects with diabetes and/or impaired glucose tolerance had high insulin levels, which was interpreted as a sign of resistance to the actions of insulin. Initial research efforts focused on syndromes of severe insulin resistance, to maximize impact, and also on the search for circulating antibodies against insulin or its receptor. It was soon realized that such receptors were responsible for severe insulin resistance in a minority of subjects, and thus the search continued at the molecular level with a focus on receptor and post-receptor defects.

\section{Insulin receptor and signaling}

Insulin exerts its biological effects by binding to the insulin receptor (INSR). Since the homology between INSR and insulin-like growth factor-1 (IGF-1) receptor is high, insulin and IGF may bind and activate either receptor or the hybrid INSR/IGF-1 receptor (1-3). INSR is a cell surface heterotetrameric glycoprotein that belongs to the receptor tyrosine kinase superfamily and is composed of two extracellular $\alpha$ subunits and two transmembrane $\beta$ subunits linked by disulfide bridges. INSR has two isoforms, $\mathrm{A}$ and $\mathrm{B}$, generated by alternate splicing of the mRNA. Isoform $\mathrm{B}$ also includes exon 11 , which encodes a

Conflict of interest: CSM reports grants and compensation from Coherus BioSciences, grants from Novo Nordisk, grants from Eisai, compensation from Ansh Labs, and compensation from Aegerion.

Copyright: (c) 2021, American Society for Clinical Investigation.

Reference information: J Clin Invest. 2021;131(4):e142245.

https://doi.org/10.1172/JCl142245. 12-amino acid sequence in the carboxy terminal and associates with more intense insulin binding. Conversely, isoform $\mathrm{A}$, which excludes exon 11, demonstrates similar affinity for insulin and IGF-2 $(1,2)$. Isoform $\mathrm{A}$ is expressed highly during fetal development and in the brain, while isoform $B$ is expressed in the liver. The two isoforms associate with minor downstream signaling differences (4). Ligand binding activates downstream phosphorylation events to ultimately recruit and activate receptor substrates, including the key insulin receptor substrate (IRS) and Shc proteins. The PI3K/AKT and the Ras/MAPK pathway are subsequently activated, controlling many aspects of metabolism and growth, such as cell cycle and survival functions, glycogen synthesis, and lipid synthesis (ref. 1 and Figure 1).

Abnormalities at any point of the insulin signaling pathway cascade could contribute to the pathogenesis of severe insulin resistance, though molecules upstream in the cascade have, theoretically, a more pronounced effect. Severe insulin resistance could also result from suboptimal insulin availability due to insulin molecule mutations that render insulin bioinactive or suboptimally active, albeit still immunoreactive, or from enzymatic degradation in the subcutaneous space of administered insulin.

\section{Definition}

Insulin resistance is one of the most prominent metabolic disorders, in which insulin action is impaired in target tissues. It is traditionally defined as suboptimal action of a given circulating concentration of insulin to control carbohydrate metabolism (5). Since insulin has various functions in humans, compensatory hyperinsulinemia that may result from an inability to control carbohydrate metabolism usually has adverse physiological outcomes in other organs and systems. Insulin resistance thus constitutes a common underlying pathophysiological condition for many clinical disorders, usually grouped under the term "metabolic syndrome." 


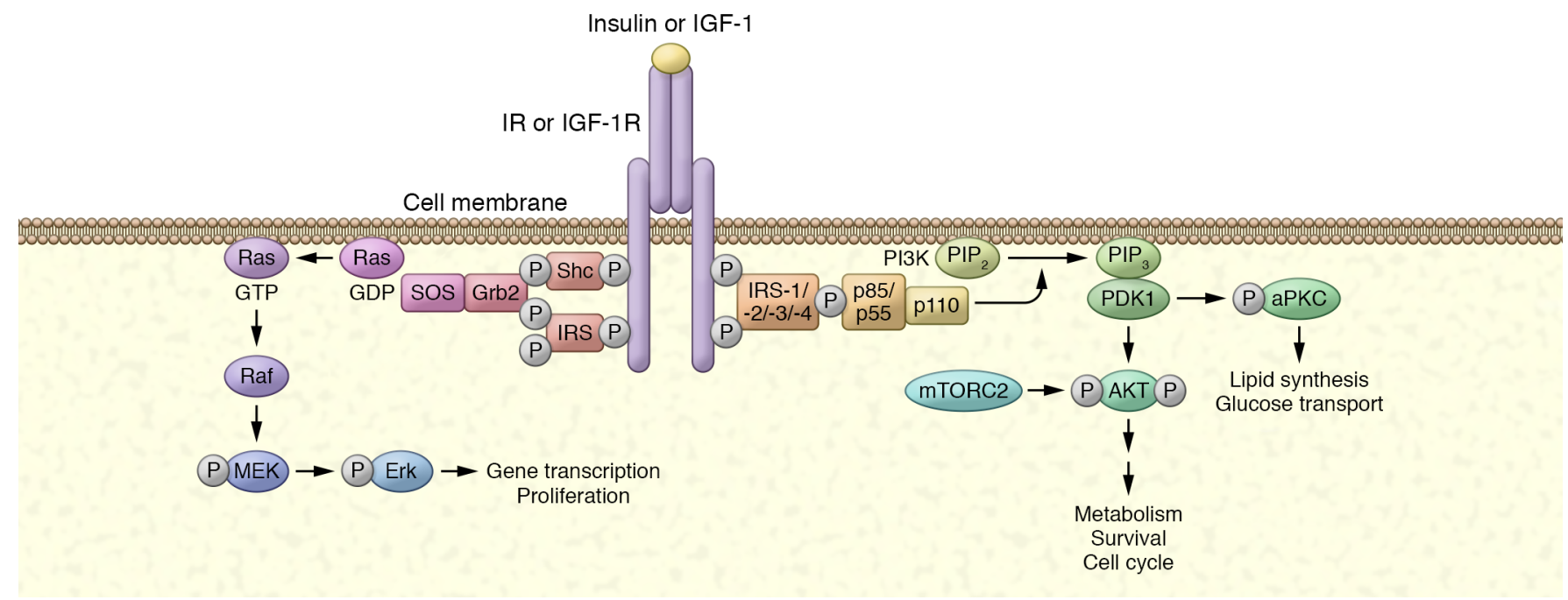

Figure 1. Insulin and IGF-1 signaling pathways intersect. Insulin receptor and IGF-1 receptor activation initiates a cascade of phosphorylation events. At the time of ligand binding the receptors change conformation and autophosphorylate, leading to the recruitment and phosphorylation of receptor substrates, such as IRS and Shc proteins. Shc activates the Ras/MAPK pathway, whereas IRS protein recruits PI3K to activate the PI3K/AKT pathway, leading to the generation of the second messenger PIP . Membrane-bound PIP $_{3}$ then recruits and activates PDK1, which phosphorylates and activates AKT and atypical PKCs (aPKC). AKT mediates most of insulin's metabolic effects and regulates the cell cycle and cell survival. The Shc/Grb2/SOS/Ras/Raf/MAPK pathway controls cellular proliferation and gene transcription.

Severe insulin resistance syndromes are a group of rare syndromes characterized by profound insulin resistance. The prevalence of severe insulin resistance syndromes is not well documented but may reflect $0.1 \%-0.5 \%$ of the patients attending hospital-based diabetes clinics (6). Severe insulin resistance may be defined as a severely diminished response to insulin's biological effects, and is characterized by substantial hyperinsulinemia and impaired glucose response to endogenous and exogenous insulin. Severe insulin resistance may present with abnormal glucose homeostasis, requiring large amounts of exogenous insulin to maintain euglycemia. Notably, patients may also show hypoglycemia (especially in disorders such as Rabson-Mendenhall syndrome), which may precede hyperglycemia $(6,7)$.

\section{Clinical features}

Severe insulin resistance syndromes show variable metabolic traits and diverse clinical manifestations. Identifying shared features may increase clinical awareness when considering cases of insulin resistance. Along with skin tags, acanthosis nigricans, a velvety hyperpigmented thickening of the skin, is an early sign and a common cutaneous manifestation of severe insulin resistance. The precise pathogenesis is not fully understood, but evidence suggests that high circulating insulin levels cross-react with the IGF-1 receptor on keratinocytes and dermal fibroblasts (8). Among women, ovarian dysfunction and hyperandrogenism are also common features. Hirsutism, polycystic ovaries, menstrual irregularities, or oligomenorrhea usually constitute the primary clinical manifestation in affected females. Hyperinsulinemia, in particular the synergy of insulin and gonadotropins, is implicated in the pathogenesis of polycystic ovary syndrome and ovarian hyperandrogenism (6). HAIR-AN hyperandrogenism, insulin resistance, and acanthosis nigricans is now considered a subphenotype of the polycystic ovary syndrome and a generic description of severe insulin resistance (6). Other clinical features observed in some of the severe insulin resistance syndromes include dyslipidemia, namely hypertriglyceridemia; nonalcoholic fatty liver disease; adipose tissue loss; abnormal adipose topography; abnormal musculature; acromegaloid features; and other growth disorders (Figure 2).

\section{Diagnostic strategies}

In order to determine the presence and severity of insulin resistance, several tests have been proposed. Apart from fasting glucose levels, and the mixed meal and glucose tolerance tests, fasting insulin levels above $50-70 \mu \mathrm{U} / \mathrm{mL}$ or levels that exceed 350 $\mu \mathrm{U} / \mathrm{mL}$ after an oral glucose tolerance test may indicate severe insulin resistance (9). However, circulating insulin concentration is dynamically variable, changing over time during the evolution of diabetes. In the research setting, other techniques to assess insulin resistance include the euglycemic clamp, considered the gold standard, and the simpler intravenous glucose tolerance test, which captures up to $90 \%$ of the variability as assessed by the clamp technique $(10,11)$. In large-population epidemiology studies, an even simpler test, the homeostasis model assessment of insulin resistance index or the quantitative insulin sensitivity check index, can, despite limitations, evaluate insulin resistance and/or pancreatic responses. These tests may capture insulin resistance variability (up to $80 \%$ as calculated by the clamp technique) adequate for large epidemiology studies $(10,12)$. Importantly, no universally accepted diagnostic biochemical criteria of severe insulin resistance in the clinical setting exist.

Generally, when evaluating patients with severe phenotypes of insulin resistance, clinicians should measure and interpret fasting insulin and C-peptide in the context of circulating glucose levels. Marked hyperinsulinemia should prompt further evaluation to detect degraded insulin in subcutaneous tissue, the presence of insulin or INSR mutations, and the presence of circulating anti-IN- 
A

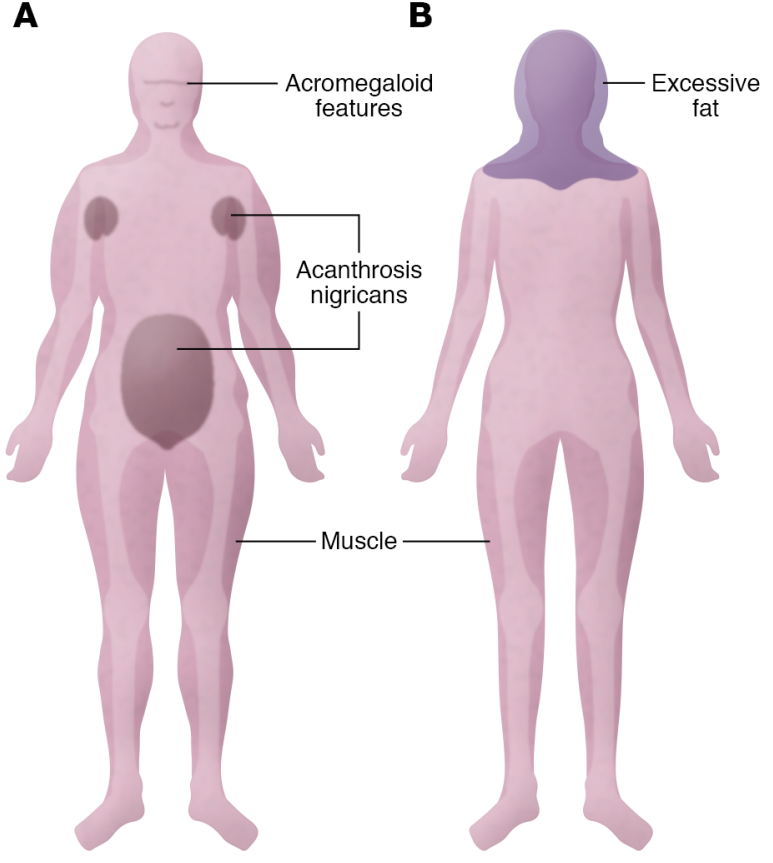

CGL1/2

Generalized lack of fat Extreme muscularity

D

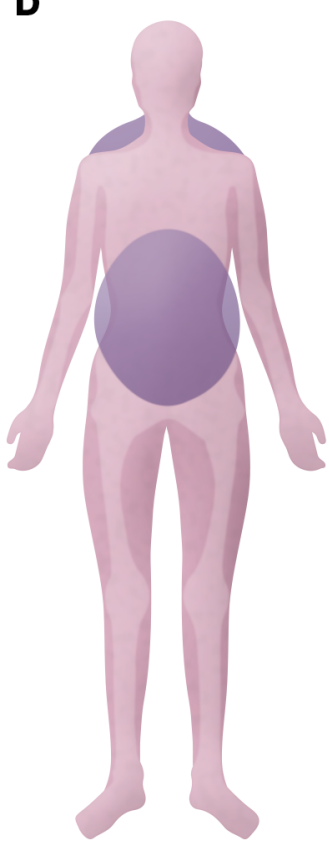

Retroviral therapyassociated lipodystrophy Lack of fat in face, arms, legs Excessive fat in abdomen Excessive fat in upper back, neck ("buffalo hump")
Familial partial lipodystrophy (Dunnigan variety) Lack of fat in arms, legs, trunk Excessive fat in face, neck

$\mathbf{E}$

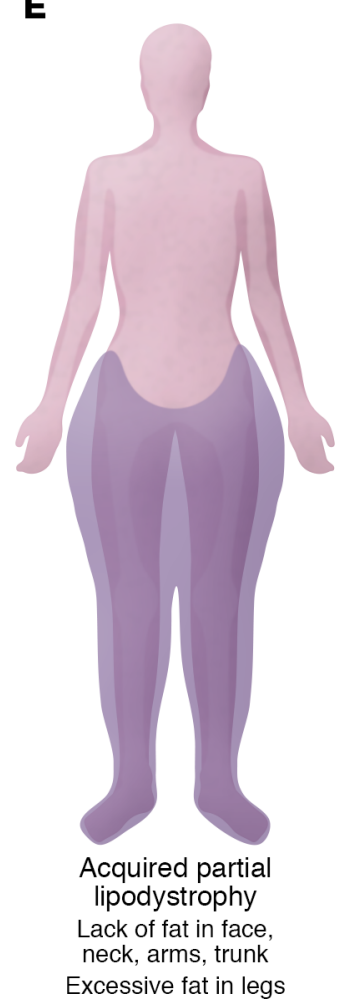

C

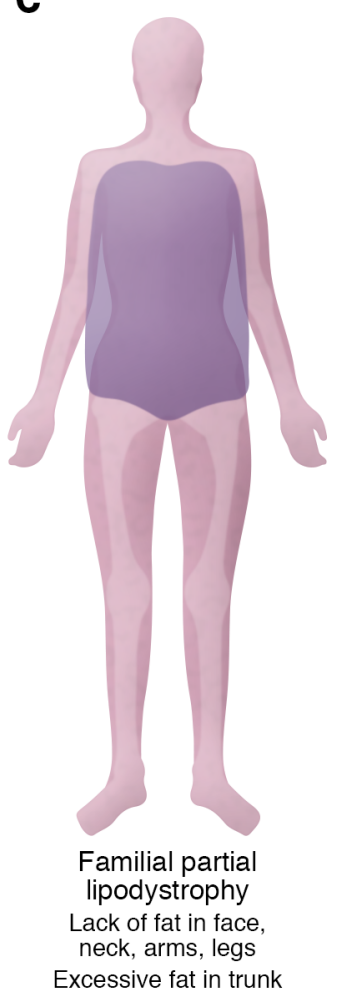

$\mathbf{F}$

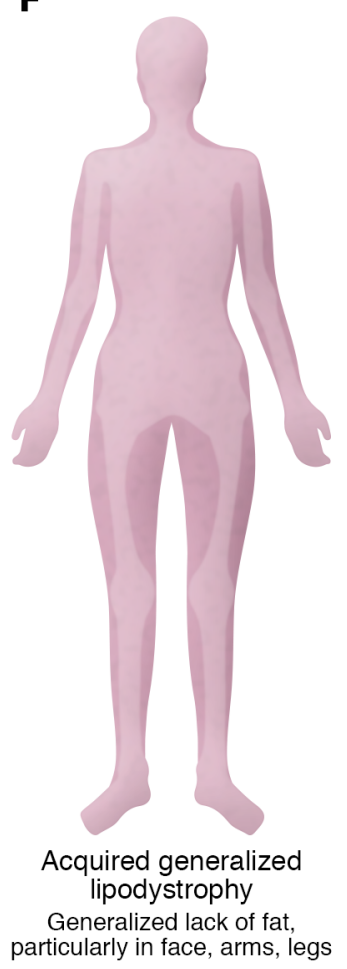

Figure 2. Patients with congenital generalized, familial partial, and acquired lipodystrophies display selective and variable adipose tissue loss. (A) CGL1 and CGL2 may present with a generalized lack of fat, extreme muscularity, acanthosis nigricans in the groin, abdomen, or axillae, and acromegaloid features. (B) Familial partial lipodystrophy such as the Dunnigan variety may manifest as loss of fat from the trunk and upper and lower extremities and excess fat accumulation in the face and neck. (c) Other familial partial lipodystrophies are characterized by loss of fat from the face, neck, arms, and legs and excess fat accumulation in the trunk. (D) Similarly, acquired lipodystrophy associated with HIV infection may display as loss of fat from the face, arms, and legs; in certain cases, increased abdominal fat; and a "buffalo hump." (E) Acquired partial lipodystrophy is characterized by loss of subcutaneous fat from the face, neck, arms, thorax, and abdomen and simultaneously excessive amounts of subcutaneous fat in the legs. (F) Acquired generalized lipodystrophy is characterized by loss of fat from large areas of the body, particularly the face, arms, and legs.

mate the leptin levels. Clinical characteristics play a crucial role in the diagnosis; for instance, in congenital generalized lipodystrophy (CGL), the phenotype is so striking that diagnosis can be made at manifestation and/or even at birth.

On the other hand, genetic advances have had a tremendous impact on confirmation of diagnoses for most genetic forms of severe insulin resistance. Nowadays, many facilities provide genetic testing services. However, because of the rarity of these syndromes, laboratory tests, such as those that identify anti-insulin receptor antibodies (type $B$ insulin resistance syndrome), are generally unavailable and may require collaborating with research laboratories.

Beyond anti-insulin receptor antibodies (13), the genetic causes of severe insulin resistance include primary insulin signaling defects due to mutations and defects in the INSR gene (1), and impaired adipocyte development, apoptosis, or function (14). Advances in genetics have driven progress in the field by allowing us to identify several genes responsible for severe insulin resistance and providing an accurate diagnosis of the related

SR antibodies, and to clinically identify characteristics associated with severe insulin resistance and various lipodystrophic disorders.

Moreover, in patients with complete lipodystrophy and potential leptin deficiency, determining leptin levels is paramount prior to initiating treatment. A specific laboratory test is required to esti- syndrome(s). Despite the rarity of severe insulin resistance syndromes, studying these diseases can provide general insights into the pathophysiological mechanisms of insulin resistance. Notably, examination of the underlying pathophysiological mechanisms of lipodystrophies has offered essential informa- 


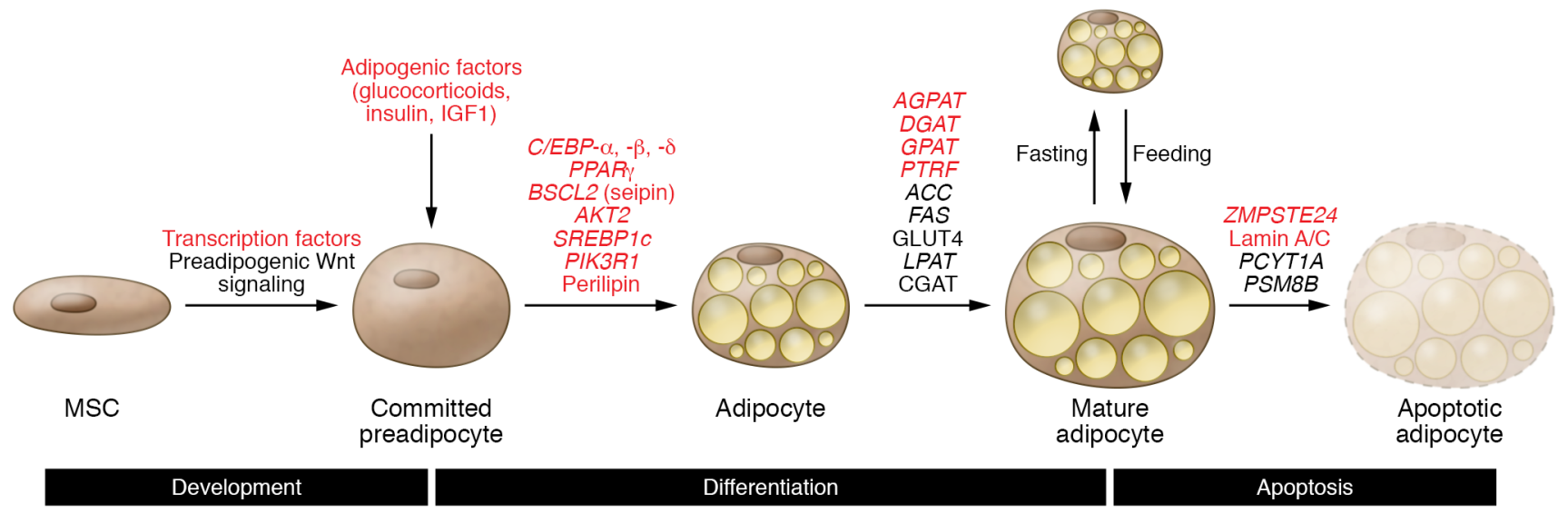

Figure 3. Molecular pathways implicated in adipogenesis and genes that may lead to the development of lipodystrophy. Several molecular pathways are implicated in the development, differentiation, and apoptosis of adipocytes. The multipotent mesenchymal stem cell (MSC) serves as an adipocyte precursor. Transcription factors promote adipocyte differentiation from mesenchymal stem cells to committed preadipocytes, then to adipocytes. Preadipocytes respond to adipogenic stimuli to initiate cell differentiation to mature adipocytes. Many genes implicated in the adipocyte differentiation process are involved in the potential development of lipodystrophy (red text indicates genes or factors discussed in this Review).

tion not only regarding the management of these rather rare syndromes but also regarding other metabolic diseases, such as obesity, type 2 diabetes, and nonalcoholic fatty liver disease.

Beyond genetics, adipose tissue as an active endocrine organ produces several cytokines and bioactive mediators, such as leptin, adiponectin, and inflammatory cytokines, that regulate insulin sensitivity homeostasis, lipid metabolism, blood pressure, and inflammation $(15,16)$.

Ectopic fat deposition, when adipose tissue storage space is insufficient (e.g., metabolically unhealthy obesity), and/or, conversely, extreme lipoatrophy, in which adipose tissue stores are nonexistent, leads to hypoleptinemia, abnormal adiponectin levels, and insulin resistance (17-19).

Adiponectin, an adipokine abundantly expressed in white and brown adipose tissue, is inversely proportional to adipose tissue, especially centrally deposited adipose tissue (20). Adiponectin exerts a potent insulin-sensitizing action through its receptors, AdipoR1 and AdipoR2, which activate AMP-activated protein kinase (AMPK) and peroxisome proliferator-activated receptor- $\alpha(\operatorname{PPAR} \alpha)$ signaling pathways $(15,20)$. Decreased adiponectin levels associate with conditions closely linked to insulin resistance, such as type 2 diabetes, hypertension, and cardiovascular disease (21-24). The adipokine leptin regulates appetite, body fat mass, metabolism, glucose homeostasis, insulin sensitivity, fatty acid oxidation, and neuroendocrine and reproductive function $(25,26)$. Leptin mediates its actions through several signal transduction pathways, including the Janus kinase (JAK)/signal transducer and activator of transcription 3 (STAT3) pathway, involved with energy homeostasis and possibly neuroendocrine function $(15,27)$. Several leptin-deficient syndromes or leptin resistance states associate with insulin resistance and diabetes (27), including severe insulin resistance in lipoatrophic subjects. Since leptin receptor and insulin receptor pathways overlap, e.g., the JAK/STAT3, AMPK, and PI3K pathways, leptin therapy may contribute to the leptin-mediated attenuation of insulin resistance directly, as well as indirectly through CNS or peripheral actions (27). Systemic inflammation caused by proinflammatory cytokines such as TNF- $\alpha$ and IL- 6 is directly correlated to the amount of adipose tissue (28). In these phenotypically severe insulin-resistant syndromes, there is chronic exposure to proinflammatory mediators, which may interrupt insulin signaling in the $\beta$ cells of pancreatic islets and also induce insulin resistance in both liver and adipocytes $(28,29)$.

Understanding the regulation of adipose tissue biology in lipodystrophy has implications for understanding the pathogenesis of common disease conditions and provides the opportunity to identify metabolic pathways responsible for insulin resistance.

This Review focuses on syndromes of severe insulin resistance. The following sections discuss severe insulin resistance syndromes related to INSR signaling defects (as seen in Donohue syndrome, Rabson-Mendenhall syndrome, and type A and B syndromes) and hereditary and acquired lipodystrophies, as well as rare conditions that demonstrate features of profound insulin resistance (Supplemental Table 1; supplemental material available online with this article; https://doi.org/10.1172/JCI142245DS1).

\section{Defects of insulin signaling}

\section{Insulin receptor defects}

Mutations related to the $\alpha$ subunit of INSR may decrease the number of available mature INSRs or the affinity of INSR for insulin binding. Furthermore, mutations related to $\beta$ subunit tyrosine kinase domain may impair autophosphorylation, affecting the activation of downstream signaling cascades $(30,31)$. Genetic causes of insulin resistance from mutations in the INSR gene have been recognized in rare recessively inherited disorders including Donohue syndrome, Rabson-Mendenhall syndrome, and type A insulin resistance syndrome (1).

Donohue syndrome. Donohue syndrome (leprechaunism) is an extremely rare autosomal recessive disease caused by mutations in the INSR gene. It was first described in 1954 (32) and represents the most severe defective insulin signaling syndrome. Diagnosis is 
based on genetic, biochemical, and clinical characteristics, while functional analyses try to reveal potential genotype/phenotype and structure/phenotype correlations based on the severity of INSR mutations $(33,34)$. Affected individuals seldom live beyond infancy, with most surviving less than 2 years, mainly due to intercurrent infection $(6,7,35)$. While there is no known etiology, in a few cases, decreased immunoglobulin levels, mainly IgG and IgA, with intact cellular and humoral immunity, have been described (36). Normal immunoglobulin concentration, T lymphocytes, and lymphocyte proliferation have also been documented $(37,38)$. It is possible that impaired polymorphonuclear leukocyte bactericidal activity drives the pathophysiology (38).

Rabson-Mendenhall syndrome. Rabson-Mendenhall syndrome is a rare autosomal recessive disease caused by mutations in the INSR gene (39). Both Rabson-Mendenhall and Donohue syndromes present after birth and associate with growth and developmental defects (perhaps due to the defective mitogenic action of insulin; refs. 6, 40). Patients may present with extremely high insulin levels (41), fasting hypoglycemia (7), and failed responses to endogenous and exogenous insulin, ultimately developing refractory diabetes mellitus, severe ketoacidosis, and microvascular diabetes complications $(7,9,41)$. Most individuals develop symptoms early in life but live into their 20 s $(1,39)$. Suspected cases based on the particular clinical manifestations and laboratory findings are confirmed with genetic testing (42).

Type A insulin resistance syndrome. Type A insulin resistance syndrome is also a rare severe insulin resistance syndrome caused by mutations in INSR. Heterozygous and, in some cases, homozygous INSR mutations impair insulin receptor function and signal transduction (43-45). Individuals with type A insulin resistance syndrome can live beyond middle age (34). Diagnosis remains challenging, though early and accurate identification is essential for targeted treatment.

\section{Insulin receptor antibodies}

Type B insulin resistance syndrome. Type B insulin resistance syndrome is an infrequent autoimmune disorder caused by polyclonal autoantibodies (usually IgG) against insulin receptors.

Experimental findings suggest that the autoantibodies act biphasically, inducing hypoglycemia in the first (acute) phase while ultimately causing hyperglycemia. The first phase associates with activation of the tyrosine kinase receptor followed by a progressive receptor downregulation and an increased degradation and subsequent reduction in cellular insulin receptors, resulting in insulin resistance and hyperglycemia (46). It has also been proposed that high autoantibody concentrations antagonize (inhibit) the INSR, leading to insulin resistance and hyperglycemia, while low levels partially agonize to elicit hypoglycemia (46-48). Consequently, patients exhibit profound insulin resistance and hyperglycemia, though hypoglycemia may less frequently occur.

Usually, type B insulin resistance syndrome manifests in adulthood with high 10 -year mortality risk $(49,50)$, occurs in middle-aged women, and associates with other autoimmune conditions (such as systemic lupus erythematosus, Sjögren syndrome, and mixed connective tissue disease) or is a manifestation of an underlying malignancy, such as Hodgkin disease and myeloma (49-52).

\section{Lipodystrophies}

Lipodystrophies are a heterogeneous group of rare disorders with approximately 1.3-4.7 cases per million (53) and even fewer for genetic lipodystrophies (54). Lipodystrophies are primarily characterized by complete or partial loss of adipose tissue and depletion of lipid storage capacity $(55,56)$. However, in some cases, specific body areas possess excess adipose tissue (57). In previous decades, evidence has emphasized the critical role of white adipose tissue as an active endocrine organ that efficiently stores excess energy. Based on etiology, lipodystrophy syndromes are either congenital or acquired. According to the extent of adipose tissue deficiency, we have characterized lipodystrophy syndromes as generalized or partial, such that four categories include congenital generalized lipodystrophy, acquired generalized lipodystrophy, congenital partial lipodystrophies, and acquired partial lipodystrophies. Other identified genetic causes (Figure 3) and pathophysiological pathways linked to lipodystrophy challenge the above classification (58).

Currently, no formal criteria exist. Despite progress in genetic characterization, a lipodystrophy diagnosis is based on medical history, clinical features, body composition, and metabolic status (55). Lipodystrophic syndromes are often misdiagnosed, or underdiagnosed, because of their scarcity, heterogeneity, and doctors' perceptions. Notably, many patients, especially those with generalized lipodystrophy, possess low leptin levels. Leptin participates in energy homeostasis, lipid metabolism, and insulin action (59). Despite proposed pathophysiological pathways (60), the exact mechanism by which leptin mediates clinical heterogeneity of the lipodystrophies remains unclear. Although leptin may act peripherally (white adipose tissue, liver, and muscle), affecting appetite, food intake, and lipid and glucose metabolism (60-62), the CNS likely mediates these energy-related effects (63).

The extent of adipose loss and alterations in adiposity is associated with the severity of metabolic derangements and related complications $(64,65)$. Metabolic disorders, and especially insulin resistance, are present in nearly all types of lipodystrophy. Additionally, more severe clinical presentation usually accompanies more severe insulin resistance. Patients can also develop severe hyperlipidemias, namely hypertriglyceridemia, inadequately controlled diabetes, progressive hepatic disease, and increased metabolic rate $(66,67)$.

\section{Congenital generalized lipodystrophy}

CGL was described initially in 1954 by Berardinelli and five years later by Seip $(68,69)$. CGL represents rare but clinically prominent disorders with an almost complete lack of adipose presenting from birth (70).

CGL is inherited in an autosomal recessive manner with high prevalence among isolated communities or in cases of parental consanguinity (71). Until now, approximately 300 patients from different ethnic groups have been described (70, 72-76). Patients have a characteristic muscular phenotype due to a near-complete absence of adipose tissue (including subcutaneous and intra-abdominal), usually apparent at birth or during early infancy. Depending on the underlying genetic cause, CGL may spare the supportive adipose tissue such as orbits, palms, soles, and joints (77). Increased insulin levels and a hyperandrogenic state may 
also contribute to prominent musculature. Other manifestations include acanthosis nigricans, acromegaloid features (70, 73), mental retardation (75), polycystic ovarian syndrome, and hypertrophic cardiomyopathy $(78,79)$.

Individuals with CGL may develop several metabolic disorders and comorbidities, affecting women more severely $(72,73$, $80)$. Insulin resistance may be present at an early age, even at birth. However, diabetes mellitus often develops in adolescence or early adulthood and is usually refractory to insulin therapy; ketosis is rare. Furthermore, diabetes-related complications, such as nephropathy and retinopathy, constitute a notable cause of morbidity. CGL is also associated with early-onset and progressive severe hypertriglyceridemia, leading to acute pancreatitis, fatty liver disease, and cirrhosis. Notably, individuals with CGL, regardless of age or sex, usually exhibit clinically low leptin levels $(60,81)$.

There are at least four molecularly distinct CGL types, with types 1 (CGL1) and 2 (CGL2) dominating the cases. AGPAT2 and BSCL2 gene mutations are responsible for CGL1 and CGL2, respectively. AGPAT2 is predominantly expressed in white adipocytes (82) and involved in the acylation process of lysophosphatidic acid to phosphatidic acid, which has a crucial role in triacylglyceride and glycerophospholipid biosynthesis (83). AGPAT2 deficiency associates with impaired signaling of critical elements such as PI3K/AKT and PPAR $\gamma$, affecting adipogenesis and reducing the levels of stored triglycerides inside the adipose (84). At least 150 cases and 42 AGPAT2 mutations have been published, and the number of related variants has increased over time $(85,86)$.

Individuals with CGL2 exhibit a more severe disease phenotype demonstrating an intense absence of body fat, including mechanical adipose depots (77). Moreover, the prevalence of diagnosed intellectual impairment is higher in patients with CGL2 (70, 75), who can develop cardiomyopathy even at a young age (78). At least 36 mutations of BSCL2 and 167 individuals with these mutations have been described (85). The BSCL2 gene encodes the seipin protein, which is involved in lipid droplet formation and adipocyte differentiation $(74,87)$. BSCL2 participates in the biosynthesis of glycerophospholipids and triacylglycerides (83), and mutations may impair adipogenesis, the expression of enzymes (AGPAT2, DGAT2, and lipin-1), and lipogenic transcription factors (PPAR $\gamma$ and CCAAT/enhancer-binding protein- $\alpha$ [C/EBP- $\alpha])(88-90)$.

Type 3 CGL (CGL3) is linked to CAV1 gene mutations affecting caveolin-1 function. Caveolin-1 constitutes part of the plasma membrane microdomains (caveolae), and is involved in cell migration, polarization, and proliferation (91). Caveolin-1 is also necessary for protein kinase A-mediated (PKA-mediated) phosphorylation of perilipin, which regulates lipolysis (92). Moreover, caveolin-1 loss associates with decreased de novo lipid droplet accumulation and a subsequent white adipose tissue atrophy (92). Caveolin-1 serves functional and structural roles in the biogenesis, accumulation, and metabolism of lipid droplets.

Type 4 CGL (CGL4) associates with mutations identified in the polymerase I and transcript release factor (PTRF) gene, also known as CAVIN-1 (93). Cavin-1 is a peripheral membrane protein and a structural component of caveolae. Moreover, Cavin-1 regu- lates caveolin-1 and -3 expression (93) and stabilizes and assembles the membrane structure, probably via the cytoskeleton (93, 94). Functionally, Cavin-1 modulates adipocyte differentiation and the expandability of adipose tissue $(94,95)$. Infants with CGL4 may show progressive body fat loss that can also include facial adipose tissue.

\section{Congenital partial lipodystrophies}

Congenital partial lipodystrophies are a group of distinct genetic syndromes characterized by regional lipoatrophy.

Familial partial lipodystrophies. The majority of familial partial lipodystrophy (FPLD) syndromes are inherited in an autosomal dominant manner and demonstrate varying degrees of subcutaneous fat loss. While there are six main FPLD types, other genetic syndromes also display partial lipodystrophy characteristics, resulting in substantial genetic and phenotypic variability (58, $96,97)$. The adipose fat loss usually occurs earlier in girls, and is evident during late childhood or puberty $(14,97,98)$. Some clinical characteristics and metabolic derangements include insulin resistance, hyperglycemia, diabetes, acanthosis nigricans, hypertriglyceridemia, hepatic steatosis, nonalcoholic steatohepatitis, ectopic fat deposition, hyperandrogenemia, hirsutism, polycystic ovarian syndrome, reproductive dysfunction, osteoporosis, cardiomyopathy, and cardiovascular disease (97).

FPLD1, or Köbberling-type lipodystrophy, follows a polygenic inheritance pattern and is characterized by distal lipoatrophy and visceral adiposity $(99,100)$. Little is known about the pathological mechanisms.

FPLD2, or Dunnigan-type lipodystrophy, associates with autosomal dominant mutations of the LMNA gene and is the most common FPLD type (more than 500 reported cases; ref. 97). LMNA encodes lamin A and C proteins, which provide structural support to the nuclear envelope. Defects in these proteins may impair interaction with chromatin or other nuclear lamina proteins, leading to adipocyte apoptosis and premature death (101). Prelamin A accumulation may interfere with adipocyte transcription factors or regulators, such as sterol response element-binding protein 1 (SREBP1) and PPAR $\gamma$, disrupting adipogenesis (101-104). Recent findings indicate that females experience a more severe disease course, due to glucocorticoid receptor GR $\beta$ overexpression or increased proinflammatory cytokine levels (105).

FPLD3 results from mutations in PPARG, which regulates adipocyte differentiation and function. FPLD3 is the second most common FPLD (approximately 20 families) and manifests similarly to FPLD1; however, affected patients tend to have more severe hypertriglyceridemia and hypertension $(97,106)$. Heterozygous mutations may attenuate gene expression or interfere directly with normal gene function (dominant negative) and inhibit adipocyte differentiation.

FPLD4 has been described in four families with autosomal dominant mutations in the PLIN1 gene, encoding perilipin-1 (97). Perilipin-1 is the most abundant phosphoprotein in adipocytes and a principal component of lipid droplet membranes. Perilipin-1 participates in lipid storage and lipolysis by regulating hormone-sensitive lipase (HSL) and adipose tissue triglyceride lipase (ATGL), which catalyze the hydrolysis of diacylglycerol and triacylglycerol into monoacylglycerol and fatty acids (107). 
FPLD5 and FPLD6 are autosomal recessive syndromes due to mutations in the cell death inducing DFFA like effector c (CIDEC) and lipase E, hormone sensitive type, (LIPE) genes, respectively. The CIDEC gene is involved in the differentiation of adipocytes. Moreover, CIDEC protein is a main regulator of lipid and glucose metabolism. It has been proposed that CIDEC mutations cause defects in adipocyte differentiation and the inability of lipid droplets to accumulate fat $(108,109)$. The LIPE gene encodes hormone-sensitive lipase, which associates with adipocyte function and lipid and glucose homeostasis. Pathological mutations of hormone-sensitive lipase may lead to impaired lipolysis, insulin resistance of small adipocytes, and inflammation (110).

Mandibuloacral dysplasia. Mandibuloacral dysplasia (MAD) is a rare autosomal recessive syndrome identified in approximately 40 cases $(10,73)$. It is characterized by craniofacial, skeletal, and cutaneous abnormalities, including mandibular and clavicular hypoplasia, birdlike face, joint contractures, dental anomalies, acroosteolysis, cutaneous pigmentation, and alopecia. Progeroid features and dysmorphic manifestations may be present at birth and become more prominent with age (98).

Two MAD types reflect the mutations: MAD type $\mathrm{A}$ is caused by mutations of the lamin A/C (LMNA) gene, which encodes nuclear lamina proteins. MAD type $\mathrm{B}$ associates with zinc metalloprotease (ZMPSTE24) genetic mutations and a more generalized loss of subcutaneous adipose tissue $(111,112)$. ZMPSTE24 is required for posttranslational proteolytic processing of carboxy-terminal residues of prelamin A to form mature lamin A. Specifically, the prelamin A contains a carboxy-terminal cysteine that is posttranslationally modified (farnesylated) to link with the plasma membrane. Subsequently, ZMPSTE24 catalyzes proteolytic cleavage and facilitates removal of 15 additional carboxy-terminal residues. ZMPSTE24 mutations may lead to the accumulation of the toxic farnesylated form of prelamin A, disrupting nuclear function in several tissues (54). Some patients may experience metabolic complications such as insulin resistance, hyperinsulinemia, diabetes, and hyperlipidemia (113).

SHORT syndrome. SHORT syndrome (short stature; hyperextensibility of joints; ocular depression; Rieger anomaly; teething delay) associates with autosomal dominant mutations of the PI3K p $85 \alpha$ regulatory subunit 1 (PIK3R1) gene, which encodes the PIK3R1 protein (regulatory p85a subunit; ref. 114). The p85a subunit connects and stabilizes the p110 catalytic subunit, which determines its activity level (115). Both subunits form the phosphatidylinositol 3-kinase (PI3K) protein, which acts to catalyze the conversion of phosphatidylinositol phosphate 2 ( $\mathrm{PIP}_{2}$ ) to $\mathrm{PIP}_{3}$. $\mathrm{PIP}_{3}$ activates the AKT signaling pathway, which regulates cellular functions including differentiation, cell survival, and insulin's biological actions $(114,115)$.

\section{Acquired generalized lipodystrophy}

Acquired generalized lipodystrophy (AGL), or Lawrence syndrome, is a rare syndrome (approximately 80 patients) with female dominance $(10,106)$ and develops in patients with a negative family history, usually during childhood or adolescence $(73,116)$. Most patients with AGL demonstrate low leptin and markedly reduced adiponectin levels, which may associate with severe insulin resistance and related metabolic complications (117). The pathogenic mechanism is unknown. However, several cases coincided with autoimmune or inflammatory diseases, such as panniculitis, Sjögren syndrome, juvenile-onset dermatomyositis, rheumatoid arthritis, systemic sclerosis, and systemic lupus erythematosus $(116,118,119)$. Most recent findings implicate anti-adipocyte antibodies predominantly directed against perilipin-1 (120-122). It has been proposed that autoantibodies, complement activation, and proinflammatory cytokines including TNF- $\alpha$ and IL- 1 contribute to AGL by impairing fat uptake, adipocyte differentiation $(50,118$, $123)$, or adipogenesis (124) or increasing receptor-mediated apoptosis of adipocytes/preadipocytes $(125,126)$.

\section{Acquired partial lipodystrophy}

Acquired partial lipodystrophy, also known as Barraquer-Simons syndrome, is one of the most common forms of acquired lipodystrophy (10). It shows a higher prevalence in females and may follow a viral infection $(127,128)$. Approximately 250 cases, primarily in patients of European descent $(57,73,129)$, have been reported manifesting clinical symptoms during childhood or adolescence. The etiology is still uncertain; however, autoimmune-mediated destruction of adipocytes has been proposed. Most patients possess circulating autoantibody known as C3 nephritic factor and low complement component 3 (C3) levels. Importantly, C3 nephritic factor stabilizes C3 convertase enzyme, increasing the half-life of the convertase by blocking C3 degradation, resulting in excessive C3 activation (73). Moreover, low C3 levels, circulating autoantibody called C3 nephritic factor immunoglobulin, and the presence of membranoproliferative glomerulonephritis may coincide, suggesting that inflammation plays a role $(73,130)$.

Lipodystrophy in HIV patients. The most common type of partial lipodystrophy is HIV-associated lipodystrophy syndrome (HALS), which develops in approximately $40 \%$ of patients treated with highly active antiretroviral therapy (HAART), particularly with protease inhibitors and nucleoside analog reverse transcriptase inhibitors. HALS also associates with the duration of HAART treatment (131, 132). The proposed underlying mechanisms involve increased apoptosis, impaired (pre)adipocyte differentiation $(133,134)$, suppressed adipogenesis (135), and altered expression of adipogenic transcription factors, including PPAR $\gamma$, SREBP1, C/EBP- $\alpha$, and C/EBP- $\beta$ (136). Moreover, HIV infection may inhibit adipocyte differentiation (137), while individual genetic background and inflammation processes may influence the metabolic and clinical manifestations as well as the severity of HALS (138-140). Low leptin concentration associates with reduced subcutaneous adipose tissue, while decreased adipokine levels coincide with excess visceral fat $(140,141)$.

The prevalence of metabolic syndrome varies, and may associate with HAART treatment duration, chronic inflammation, and the HIV infection itself. While safer HIV medications have decreased the prevalence of HALS (142), patients with HALS are also predisposed to an increased risk of atherosclerosis and cardiovascular disease $(143,144)$.

\section{Other complex syndromes of severe insulin resistance}

Other complex syndromes of severe insulin resistance are described in Supplemental Table 1. Subcutaneous insulin resistance syndrome is a rare condition characterized by profound resistance to the action of subcutaneous insulin while maintaining sensitivity to 
intravenous insulin, due to increased insulin-degrading activity in the subcutaneous tissue. These patients often experience recurrent episodes of life-threatening diabetic ketoacidosis (145-147).

\section{Treatment strategies}

Patients share common metabolic consequences of severe insulin resistance, such as diabetes, lipid abnormalities, and hepatic derangements, despite their marked phenotypic heterogeneity. Lifestyle modifications, oral and injectable antihyperglycemic medications, insulin, and lipid-lowering medications, along with therapies targeted to reverse or attenuate insulin resistance, constitute our modern treatment armamentarium.

\section{Diet and exercise}

Aggressive lifestyle modifications focused on calorie and, when appropriate, weight reduction and increased physical activity are key elements of the therapeutic approach (148-150). Several dietary approaches, including the Mediterranean, likely contribute to maintaining a healthy weight, improving insulin resistance, and lowering inflammatory markers and endothelial dysfunction (151, 152). Moderate-intensity physical activity daily for 30 minutes is beneficial.

Lipoatrophic patients are typically hyperphagic, reportedly secondarily to leptin deficiency. Energy-restricted diets and caloric restriction are anecdotally effective if sustained for long periods of time (55). Most patients should follow diets with the goal of attaining ideal body weight (153), while very-low-fat diets may be appropriate in cases with severe hypertriglyceridemia. Both strength and endurance training are also encouraged (154), except in cases with cardiomyopathy (155).

\section{Insulin}

Insulin directly or indirectly affects the function of nearly every tissue in the body. Insulin resistance is defined as a subnormal response to normal insulin concentrations. To overcome insulin resistance, exogenous insulin has been used. Patients with generalized lipodystrophy and patients with INSR mutations typically require higher insulin doses $(156,157)$. Since high insulin volume may result in discomfort, leakage, and impaired absorption, concentrated insulins (two or five times more concentrated than standard U-100 insulin) should be considered $(158,159)$.

\section{Insulin-like growth factor-1}

Since insulin and IGF-1 mediate their effects through similar tyrosine kinase receptors, and can interchangeably activate the alternate receptor with reduced affinity, IGF-1 is a possible therapeutic agent against insulin resistance. Recombinant human IGF-1 (rhIGF-1) can improve metabolic control in INSR-related severe insulin resistance syndromes and increase life span in patients with Donohue syndrome $(160,161)$. RhIGF-1 can be administered subcutaneously or via continuous pump infusion (162). RhIGF-1 is thought to exercise its effects on glucose homeostasis mainly by reducing hepatic gluconeogenesis and increasing glucose uptake from peripheral tissues (163). Early treatment with rhIGF-1 typically improves outcomes, although side effects prevented its approval and wide use. Currently available publications are either single case reports or include few patients, rendering a direct comparison of treatment efficacy inconclusive.

\section{Insulin sensitizers}

Metformin and thiazolidinediones (TZDs) play a crucial role in severe insulin resistance, improving glucose tolerance, in part by enhancing insulin sensitivity. TZDs or other PPAR $\gamma$ modulators also increase adiponectin levels. Metformin is considered first-line pharmacotherapy for improving insulin sensitivity in patients with lipodystrophies and may also improve fat redistribution in HALS (164). Several reports support the use of TZDs, particularly pioglitazone, to improve the metabolic profile in patients with partial lipodystrophy $(165,166)$. Only one open-label prospective study tested the troglitazone efficacy (167). Consequently, TZDs need to be used cautiously in patients with generalized lipodystrophy. Similarly, incretin-based therapies including glucagon-like peptide 1 receptor agonists and sodium glucose transporter inhibitors can be used in lipodystrophy, but their efficacy has not been studied systematically.

\section{Lipid-lowering medications}

Hyperlipidemia is usually managed with statins, fibrates, and fish oil, rich in omega-3 fatty acids $(168,169)$. No systemic studies have tested the efficacy of lipid-lowering medications in these patient populations. Combination of fibrates with statins should be used cautiously given the cumulative risk of myopathy and hepatotoxicity. Fibrates and/or long-chain omega-3 fatty acids may be considered for high triglycerides. Additional LDL-cholesterol-lowering medications, such as ezetimibe and PCSK9 (proprotein convertase subtilisin/kexin type 9) antibody inhibitors, are available, though they have not been studied specifically in this patient population. Inclisiran, a small interfering RNA, which may provide sustained LDL reductions, is a promising nonantibody approach that targets PCSK9. The efficacy of inclisiran has been demonstrated in the most recent phase III trials among patients with atherosclerotic cardiovascular disease or its equivalent and elevated LDL level (170). Several liver-specific secreted proteins have been identified as playing a key role in regulating lipid metabolism. Bempedoic acid, an inhibitor of ATP citrate lyase, alone or in combination with statin or ezetimibe, may prove beneficial (171). In 2020, bempedoic acid was approved by the FDA for heterozygous familial hypercholesterolemia. Volanesorsen is a second-generation apolipoprotein C-III antisense oligonucleotide that decreases apolipoprotein C-III, a major triglyceride regulator, and subsequently reduces triglyceride levels (172, 173). The BROADEN Study (174), a randomized, double-blind, placebo-controlled study, recruited patients with partial lipodystrophy and hypertriglyceridemia and will report the effect and safety profile of volanesorsen. Similarly, trials involving angiopoietin-like 3 (ANGPTL3) inhibition via antibodies, such as evinacumab, or antisense oligonucleotides may reveal additional targets for the treatment of hypercholesterolemia in lipodystrophy patient populations $(175,176)$. Gemcabene is another agent that can enhance the clearance of VLDL-cholesterol, increasing HDL and decreasing hepatic triglyceride synthesis. A clinical study of gemcabene for the management of hypertriglyceridemia and nonalcoholic fatty liver disease in familial partial lipodystrophy patients is ongoing (177). 


\section{Etiologic therapeutic strategies}

Leptin therapy. Metreleptin, a leptin analog, is the only drug specifically indicated for the treatment of lipodystrophy in the United States (178). In multiple prospective, albeit small and uncontrolled, studies of generalized lipodystrophy, metreleptin treatment suppressed appetite and favored metabolic profiles compatible with reducing, or even discontinuing, antidiabetic medications. Further, nonalcoholic steatohepatitis improved (179-181). In patients taking metreleptin, improved peripheral glucose disposal, hepatic glucose output, and insulin secretion lowered fasting glucose levels (182). Within weeks, triglyceride levels decreased, achieving $60 \%$ reduction after one year of treatment (66). Metreleptin has also found off-label use in partial lipodystrophy (183), with possible effectiveness in pediatric patients (184); however, the possibility of developing anti-leptin neutralizing antibodies has prompted the FDA to prevent metreleptin use for any lipodystrophies except complete lipodystrophy (185). While T cell lymphoma has been reported in individuals with acquired lipodystrophy who were treated with metreleptin, it remains unclear whether the cases represented a treatment side effect or a natural history of disease progression (186).

GHRH analog. The growth hormone-releasing hormone (GHRH) analog tesamorelin has FDA approval for use in HALS, in which it improves metabolic abnormalities associated with visceral fat accumulation $(187,188)$. Tesamorelin is administered as a subcutaneous injection daily. Several randomized clinical trials reported visceral fat reduction during treatment $(189,190)$, but rapid reaccumulation was noted after discontinuation of therapy. The possibility that tesamorelin worsens glucose intolerance through increased IGF-1 levels warrants caution (191).

Immunosuppresants. Type B insulin resistance is traditionally challenging to manage and has been treated with various forms of immunosuppression with mixed success (192). Malek et al. reported a protocol of rituximab, cyclophosphamide, and pulse steroids (49), which achieved remission in seven patients with type B insulin resistance. However, after about eight months immunosuppressive therapy was stopped and insulin resistance status remained unclear. Complementary strategies to eliminate the culprit antibody may account for the success. Cyclosporin A, azathioprine, intravenous immunoglobulins, and plasmapheresis have also been used with variable effects (193).

\section{Cosmetic surgery}

Cosmetic surgery has been effective in correcting hypo- or hypertrophic depots in patients with lipodystrophy, with positive psychological implications (55). However, this approach should ideally be coupled with modifications as outlined above.

\section{Conclusion}

This Review has discussed the pathogenesis and features of several severe insulin resistance syndromes and potential therapeutic interventions. Studying these rare conditions has historically opened new pathways in diabetes research and allowed us to gain important insights into insulin's action and physiology.

\section{Author contributions}

All authors contributed to the conception and design of the overall commissioned work. This process was chaired by CSM. All authors were involved in the drafting and revision of the report. AMA and AF led the drafting and editing process. All authors approved the final version for publication and agree to be held accountable for resolving any future questions related to the integrity or accuracy of the work.

\section{Acknowledgments}

The authors thank Pooja Bhargava for contributing to research on certain topics discussed herein and for helpful discussions. The authors received no specific funding for this work.

Address correspondence to: Christos S. Mantzoros, ASN-249, Beth Israel Deaconess Medical Center, 330 Brookline Avenue, Boston, Massachusetts 02215, USA. Phone: 617.667.8633; Email: cmantzor@bidmc.harvard.edu.
1. Boucher J, et al. Insulin receptor signaling in normal and insulin-resistant states. Cold Spring Harb Perspect Biol. 2014;6(1):a009191.

2. Malakar $P$, et al. Insulin receptor alternative splicing is regulated by insulin signaling and modulates beta cell survival. Sci Rep. 2016;6:31222.

3. Belfiore A, et al. Insulin receptor isoforms and insulin receptor/insulin-like growth factor receptor hybrids in physiology and disease. Endocr Rev. 2009;30(6):586-623.

4. Leibiger B, et al. Selective insulin signaling through $\mathrm{A}$ and $\mathrm{B}$ insulin receptors regulates transcription of insulin and glucokinase genes in pancreatic beta cells. Mol Cell. 2001;7(3):559-570.

5. Beale EG. Insulin signaling and insulin resistance. JInvestig Med. 2013;61(1):11-14.

6. Semple RK, et al. Genetic syndromes of severe insulin resistance. Endocr Rev. 2011;32(4):498-514.

7. Parker VE, Semple RK. Genetics in endocrinology: genetic forms of severe insulin resistance: what endocrinologists should know. Eur J Endo- crinol. 2013;169(4):R71-R80.

8. Cruz PD Jr., Hud JA Jr. Excess insulin binding to insulin-like growth factor receptors: proposed mechanism for acanthosis nigricans. J Invest Dermatol. $1992 ; 98$ (6 suppl):82S-85S.

9. Tritos NA, Mantzoros CS. Clinical review 97: Syndromes of severe insulin resistance. JClin Endocrinol Metab. 1998;83(9):3025-3030.

10. Grunberger G, et al. Syndromes of extreme insulin resistance. In: Poretsky L, eds. Principles of Diabetes Mellitus. Springer; 2017: 1-21.

11. Galvin P, et al. A simple method for quantitation of insulin sensitivity and insulin release from an intravenous glucose tolerance test. Diabet Med. 1992;9(10):921-928.

12. Katz A, et al. Quantitative insulin sensitivity check index: a simple, accurate method for assessing insulin sensitivity in humans. J Clin Endocrinol Metab. 2000;85(7):2402-2410.

13. Rager KM, Omar HA. Androgen excess disorders in women: the severe insulin-resistant hyperandrogenic syndrome, HAIR-AN. ScientificWorldJournal. 2006;6:116-121.
14. Melvin A, et al. Genetic syndromes of severe insulin resistance. Curr Opin Genet Dev. 2018;50:60-67.

15. Stern JH, et al. Adiponectin, leptin, and fatty acids in the maintenance of metabolic homeostasis through adipose tissue crosstalk. Cell Metab. 2016;23(5):770-784.

16. Rabe K, et al. Adipokines and insulin resistance. Mol Med. 2008;14(11-12):741-751.

17. Boutari C, Mantzoros CS. Decreasing lean body mass with age: challenges and opportunities for novel therapies. Endocrinol Metab (Seoul) 2017;32(4):422-425.

18. Boutari C, Mantzoros CS. Adiponectin and leptin in the diagnosis and therapy of NAFLD. Metabolism. 2020;103:154028.

19. Boutari C, et al. Association of adipokines with development and progression of nonalcoholic fatty liver disease. Endocrinol Metab (Seoul). 2018;33(1):33-43.

20. Kadowaki T, et al. Adiponectin and adiponectin receptors in insulin resistance, diabetes, and the metabolic syndrome. JClin Invest. 
2006;116(7):1784-1792.

21. Adamczak M, et al. Decreased plasma adiponectin concentration in patients with essential hypertension. Am J Hypertens. 2003;16(1):72-75.

22. Krakoff J, et al. Inflammatory markers, adiponectin, and risk of type 2 diabetes in the Pima Indian. Diabetes Care. 2003;26(6):1745-1751.

23. Lindberg S, et al. Adiponectin, type 2 diabetes and cardiovascular risk. Eur J Prev Cardiol. 2015;22(3):276-283.

24. Pischon T, et al. Plasma adiponectin levels and risk of myocardial infarction in men. JAMA. 2004;291(14):1730-1737.

25. Flier JS. Obesity wars: molecular progress confronts an expanding epidemic. Cell. 2004;116(2):337-350.

26. Berglund ED, et al. Direct leptin action on POMC neurons regulates glucose homeostasis and hepatic insulin sensitivity in mice. J Clin Invest. 2012;122(3):1000-1009.

27. Dardeno TA, et al. Leptin in human physiology and therapeutics. Front Neuroendocrinol. 2010;31(3):377-393.

28. de Luca C, Olefsky JM. Inflammation and insulin resistance. FEBS Lett. 2008;582(1):97-105.

29. Jaganathan R, et al. Emerging role of adipocytokines in type 2 diabetes as mediators of insulin resistance and cardiovascular disease. Can J Diabetes. 2018;42(4):446-456.

30. Hovnik T, et al. Severe progressive obstructive cardiomyopathy and renal tubular dysfunction in Donohue syndrome with decreased insulin receptor autophosphorylation due to a novel INSR mutation. Eur J Pediatr. 2013;172(8):1125-1129.

31. Escribano O, et al. The role of insulin receptor isoforms in diabetes and its metabolic and vascular complications. J Diabetes Res. 2017;2017:1403206.

32. Donohue WL, Uchida I. Leprechaunism: a euphemism for a rare familial disorder. J Pediatr. 1954;45(5):505-519.

33. Makino $\mathrm{H}$, et al. Insulin receptor gene mutation: a molecular genetical and functional analysis. Cell Signal.1992;4(4):351-363.

34. Hosoe J, et al. Structural basis and genotype-phenotype correlations of INSR mutations causing severe insulin resistance. Diabetes. 2017;66(10):2713-2723.

35. de Bock M, et al. "Donohue syndrome". JClin Endocrinol Metab. 2012;97(5):1416-1417.

36. Gross-Kieselstein E, et al. Leprechaunism (Donohue syndrome). Am J Dis Child. 1973;126(4):500-503.

37. Kostopoulou E, et al. Gastrointestinal dysmotility and pancreatic insufficiency in 2 siblings with Donohue syndrome. Pediatr Diabetes. 2017;18(8):839-843.

38. Sacchi F, et al. Staphylocidal defect of polymorphonuclear leukocytes in a patient with leprechaunism. Eur J Pediatr. 1981;137(1):89-90.

39. Grasso V, et al. Six cases with severe insulin resistance (SIR) associated with mutations of insulin receptor: is a Bartter-like syndrome a feature of congenital SIR? Acta Diabetol. 2013;50(6):951-957.

40. Falik Zaccai TC, et al. Two novel mutations iden- tified in familial cases with Donohue syndrome. Mol Genet Genomic Med. 2014;2(1):64-72.

41. Longo N, et al. Progressive decline in insulin levels in Rabson-Mendenhall syndrome. J Clin Endocrinol Metab. 1999;84(8):2623-2629.

42. Takeuchi T, et al. Clinical characteristics of insulin resistance syndromes: a nationwide survey in Japan. J Diabetes Investig. 2020;11(3):603-616.

43. Musso C, et al. Clinical course of genetic diseases of the insulin receptor (type A and Rabson-Mendenhall syndromes): a 30-year prospective. Medicine (Baltimore). 2004;83(4):209-222.

44. Iwanishi $\mathrm{M}$, et al. A mutation (Trp1193 $\rightarrow$ Leu1193) in the tyrosine kinase domain of the insulin receptor associated with type A syndrome of insulin resistance. Diabetologia. 1993;36(5):414-422.

45. Takasawa K, et al. Clinical characteristics of adolescent cases with Type A insulin resistance syndrome caused by heterozygous mutations in the $\beta$-subunit of the insulin receptor (INSR) gene. J Diabetes. 2019;11(1):46-54.

46. Censi S, et al. Insulin autoimmune syndrome: from diagnosis to clinical management. Ann Transl Med. 2018;6(17):335.

47. Willard DL, et al. Type B insulin resistance syndrome. Curr Opin Endocrinol Diabetes Obes. 2016;23(4):318-323.

48. Taylor SI, et al. Hypoglycemia associated with antibodies to the insulin receptor. $N$ EnglJ Med. 1982;307(23):1422-1426.

49. Malek R, et al. Treatment of type B insulin resistance: a novel approach to reduce insulin receptor autoantibodies. JClin Endocrinol Metab. 2010;95(8):3641-3647.

50. Arioglu E, et al. Clinical course of the syndrome of autoantibodies to the insulin receptor (type B insulin resistance): a 28-year perspective. Medicine (Baltimore). 2002;81(2):87-100.

51. Cochran $\mathrm{E}$, et al. Other antibodies resulting in diabetes mellitus: type $B$ insulin resistance and insulin autoimmune syndrome. AACE Clin Case Rep. 2016;2(3):e274-e275.

52. Martins LM, et al. Type B insulin resistance syndrome: a systematic review. Arch Endocrinol Metab. 2020;64(4):337-348.

53. Chiquette $\mathrm{E}$, et al. Estimating the prevalence of generalized and partial lipodystrophy: findings and challenges. Diabetes Metab Syndr Obes. 2017;10:375-383.

54. Garg A. Clinical review\#: Lipodystrophies: genetic and acquired body fat disorders. JClin Endocrinol Metab. 2011;96(11):3313-3325.

55. Brown RJ, et al. The diagnosis and management of lipodystrophy syndromes: a multi-society practice guideline. JClin Endocrinol Metab. 2016;101(12):4500-4511.

56. Robbins AL, Savage DB. The genetics of lipid storage and human lipodystrophies. Trends $\mathrm{Mol}$ Med. 2015;21(7):433-438.

57. Fiorenza CG, et al. Lipodystrophy: pathophysiology and advances in treatment. Nat Rev Endocrinol. 2011;7(3):137-150.

58. Araújo-Vilar D, Santini F. Diagnosis and treatment of lipodystrophy: a step-by-step approach. JEndocrinol Invest. 2019;42(1):61-73.

59. Kershaw EE, Flier JS. Adipose tissue as an endocrine organ. JClin Endocrinol Metab. 2004;89(6):2548-2556.

60. Moon HS, et al. Leptin's role in lipodystrophic and nonlipodystrophic insulin-resistant and diabetic individuals. Endocr Rev. 2013;34(3):377-412.

61. Farooqi IS, et al. Beneficial effects of leptin on obesity, $\mathrm{T}$ cell hyporesponsiveness, and neuroendocrine/metabolic dysfunction of human congenital leptin deficiency. JClin Invest. 2002;110(8):1093-1103.

62. Gallardo N, et al. Tissue-specific effects of central leptin on the expression of genes involved in lipid metabolism in liver and white adipose tissue. Endocrinology. 2007;148(12):5604-5610.

63. Prieur X, et al. Leptin regulates peripheral lipid metabolism primarily through central effects on food intake. Endocrinology. 2008;149(11):5432-5439.

64. Cortés VA, Fernández-Galilea M. Lipodystrophies: adipose tissue disorders with severe metabolic implications. J Physiol Biochem. 2015;71(3):471-478.

65. Hussain I, et al. Lipodystrophies, dyslipidaemias and atherosclerotic cardiovascular disease. Pathology. 2019;51(2):202-212.

66. Diker-Cohen T, et al. Partial and generalized lipodystrophy: comparison of baseline characteristics and response to metreleptin. J Clin Endocrinol Metab. 2015;100(5):1802-1810.

67. Polyzos SA, et al. Fatty liver in lipodystrophy: a review with a focus on therapeutic perspectives of adiponectin and/or leptin replacement. Metabolism. 2019;96:66-82.

68. Berardinelli W. An undiagnosed endocrinometabolic syndrome: report of 2 cases. JClin Endocrinol Metab. 1954;14(2):193-204.

69. Seip M. Lipodystrophy and gigantism with associated endocrine manifestations. Anew diencephalic syndrome? Acta Paediatr. 1959;48:555-574.

70. Agarwal AK, et al. Phenotypic and genetic heterogeneity in congenital generalized lipodystrophy. JClin Endocrinol Metab. 2003;88(10):4840-4847.

71. Magré J, et al. Prevalence of mutations in AGPAT2 among human lipodystrophies. Diabetes. 2003;52(6):1573-1578.

72. Premkumar A, et al. Lipoatrophic-lipodystrophic syndromes: the spectrum of findings on MR imaging. AJR Am J Roentgenol. 2002;178(2):311-318.

73. Garg A. Acquired and inherited lipodystrophies. N Engl J Med. 2004;350(12):1220-1234.

74. Szymanski KM, et al. The lipodystrophy protein seipin is found at endoplasmic reticulum lipid droplet junctions and is important for droplet morphology. Proc Natl Acad Sci U S A. 2007;104(52):20890-20895.

75. Van Maldergem L, et al. Genotype-phenotype relationships in Berardinelli-Seip congenital lipodystrophy. J Med Genet. 2002;39(10):722-733.

76. Patni N, Garg A. Congenital generalized lipodystrophies-new insights into metabolic dysfunction. Nat Rev Endocrinol. 2015;11(9):522-534.

77. Simha V, Garg A. Phenotypic heterogeneity in body fat distribution in patients with congenital generalized lipodystrophy caused by mutations in the AGPAT2 or seipin genes. JClin Endocrinol Metab. 2003;88(11):5433-5437.

78. Bhayana S, et al. Cardiomyopathy in con- 
genital complete lipodystrophy. Clin Genet. 2002;61(4):283-287.

79. Rheuban KS, et al. Hypertrophic cardiomyopathy in total lipodystrophy. J Pediatr. 1986;109(2):301-302.

80. Akinci B, et al. Phenotypic and genetic characteristics of lipodystrophy: pathophysiology, metabolic abnormalities, and comorbidities. Curr Diab Rep. 2018;18(12):143.

81. Lima JG, et al. Clinical and laboratory data of a large series of patients with congenital generalized lipodystrophy. Diabetol Metab Syndr. 2016;8:23.

82. Shindou H, et al. Recent progress on acyl CoA: lysophospholipid acyltransferase research. J Lipid Res. 2009;50(suppl):S46-S51.

83. Leung DW. The structure and functions of human lysophosphatidic acid acyltransferases. Front Biosci. 2001;6:D944-D953.

84. Subauste AR, et al. Alterations in lipid signaling underlie lipodystrophy secondary to AGPAT2 mutations. Diabetes. 2012;61(11):2922-2931.

85. Craveiro Sarmento AS, et al. The worldwide mutational landscape of Berardinelli-Seip congenital lipodystrophy. Mutat Res. 2019;781:30-52.

86. Ceccarini G, et al. Congenital generalized lipoatrophy (berardinelli-seip syndrome) type 1: description of novel AGPAT2 homozygous variants showing the highly heterogeneous presentation of the disease. Front Endocrinol (Lausanne). 2020;11:39.

87. Cartwright $\mathrm{BR}$, et al. Seipin performs dissectible functions in promoting lipid droplet biogenesis and regulating droplet morphology. Mol Biol Cell. 2015;26(4):726-739.

88. Talukder MM, et al. Seipin oligomers can interact directly with AGPAT2 and Lipin 1, physically scaffolding critical regulators of adipogenesis. Mol Metab. 2015;4(3):199-209.

89. Payne VA, et al. The human lipodystrophy gene BSCL2/seipin may be essential for normal adipocyte differentiation. Diabetes. 2008;57(8):2055-2060.

90. Chen W, et al. The human lipodystrophy gene product Berardinelli-Seip congenital lipodystrophy 2 /seipin plays a key role in adipocyte differentiation. Endocrinology. 2009;150(10):4552-4561.

91. Razani B, Lisanti MP. Caveolin-deficient mice: insights into caveolar function human disease. JClin Invest. 2001;108(11):1553-1561.

92. Cohen AW, et al. Role of caveolin-1 in the modulation of lipolysis and lipid droplet formation. Diabetes. 2004;53(5):1261-1270.

93. Hayashi YK, et al. Human PTRF mutations cause secondary deficiency of caveolins resulting in muscular dystrophy with generalized lipodystrophy. J Clin Invest. 2009;119(9):2623-2633.

94. Liu L, Pilch PF. A critical role of cavin (polymerase I and transcript release factor) in caveolae formation and organization. J Biol Chem. 2008;283(7):4314-4322.

95. Perez-Diaz S, et al. Polymerase I and transcript release factor (PTRF) regulates adipocyte differentiation and determines adipose tissue expandability. FASEB J. 2014;28(8):3769-3779.

96. Melvin A, et al. Recent developments in lipodystrophy. Curr Opin Lipidol. 2019;30(4):284-290.

97. Bagias C, et al. Familial partial lipodystrophy (fpld): recent insights. Diabetes Metab Syndr Obes. 2020;13(FPLD):1531-1544.

98. Hussain I, Garg A. Lipodystrophy syndromes. Endocrinol Metab Clin North Am. 2016;45(4):783-797.

99. Guillín-Amarelle C, et al. Type 1 familial partial lipodystrophy: understanding the Köbberling syndrome. Endocrine. 2016;54(2):411-421.

100.Lotta LA, et al. Integrative genomic analysis implicates limited peripheral adipose storage capacity in the pathogenesis of human insulin resistance. Nat Genet. 2017;49(1):17-26.

101.Agarwal AK, et al. Genetic basis of congenital generalized lipodystrophy. Int JObes Relat Metab Disord. 2004;28(2):336-339.

102. Araujo-Vilar D, et al. Site-dependent differences in both prelamin $\mathrm{A}$ and adipogenic genes in subcutaneous adipose tissue of patients with type 2 familial partial lipodystrophy. J Med Genet. 2009;46(1):40-48.

103. Capanni C, et al. Altered pre-lamin A processing is a common mechanism leading to lipodystrophy. Hum Mol Genet. 2005;14(11):1489-1502.

104. Lloyd DJ, et al. A novel interaction between lamin A and SREBP1: implications for partial lipodystrophy and other laminopathies. Hum Mol Genet. 2002;11(7):769-777.

105. Resende ATP, et al. Phenotypic diversity and glucocorticoid sensitivity in patients with familial partial lipodystrophy type 2. Clin Endocrinol (Oxf). 2019;91(1):94-103.

106.Savage DB, et al. Human metabolic syndrome resulting from dominant-negative mutations in the nuclear receptor peroxisome proliferator-activated receptor-gamma. Diabetes. 2003;52(4):910-917.

107. Chen RX, et al. The renal manifestations of type 4 familial partial lipodystrophy: a case report and review of literature. BMC Nephrol. 2018;19(1):111.

108. Rubio-Cabezas O, et al. Partial lipodystrophy and insulin resistant diabetes in a patient with a homozygous nonsense mutation in CIDEC. EMBO Mol Med. 2009;1(5):280-287.

109. Li F, et al. Cell death-inducing DFF45-like effector, a lipid droplet-associated protein, might be involved in the differentiation of human adipocytes. FEBS J. 2010;277(20):4173-4183.

110. Albert JS, et al. Null mutation in hormone-sensitive lipase gene and risk of type 2 diabetes. $N$ Engl JMed. 2014;370(24):2307-2315.

111. Agarwal AK, et al. Zinc metalloproteinase, ZMPSTE24, is mutated in mandibuloacral dysplasia. Hum Mol Genet. 2003;12(16):1995-2001.

112. Simha V, et al. Genetic and phenotypic heterogeneity in patients with mandibuloacral dysplasia-associated lipodystrophy. J Clin Endocrinol Metab. 2003;88(6):2821-2824.

113. Simha V, Garg A. Body fat distribution and metabolic derangements in patients with familial partial lipodystrophy associated with mandibuloacral dysplasia. JClin Endocrinol Metab. 2002;87(2):776-785.

114. Winnay JN, et al. PI3-kinase mutation linked to insulin and growth factor resistance in vivo. J Clin Invest. 2016;126(4):1401-1412.

115. Yu J, et al. Regulation of the p85/p110 phosphatidylinositol 3'-kinase: stabilization and inhibition of the p110alpha catalytic subunit by the p 85 regulatory subunit. Mol Cell Biol. 1998;18(3):1379-1387.

116. Misra A, Garg A. Clinical features and metabolic derangements in acquired generalized lipodystrophy: case reports and review of the literature. Medicine (Baltimore). 2003;82(2):129-146.

117. Haque WA, et al. Serum adiponectin and leptin levels in patients with lipodystrophies. JClin Endocrinol Metab. 2002;87(5):2395.

118. Pope E, et al. Childhood acquired lipodystrophy: a retrospective study. JAm Acad Dermatol. 2006;55(6):947-950.

119. Billings JK, et al. Lipoatrophic panniculitis: a possible autoimmune inflammatory disease of fat. Report of three cases. Arch Dermatol. 1987;123(12):1662-1666.

120. Corvillo F, et al. Autoantibodies against perilipin 1 as a cause of acquired generalized lipodystrophy. Front Immunol. 2018;9:2142.

121. Falcao CK, et al. Acquired lipodystrophy associated with nivolumab in a patient with advanced renal cell carcinoma. JClin Endocrinol Metab. 2019;104(8):3245-3248.

122. Jehl A, et al. Acquired generalized lipodystrophy: a new cause of anti-PD- 1 immune-related diabetes. Diabetes Care. 2019;42(10):2008-2010.

123. Bingham A, et al. Predictors of acquired lipodystrophy in juvenile-onset dermatomyositis and a gradient of severity. Medicine (Baltimore). 2008;87(2):70-86.

124. Fève B. Adipogenesis: cellular and molecular aspects. Best Pract Res Clin Endocrinol Metab. 2005;19(4):483-499.

125. Fischer-Posovszky P, et al. Role of CD95-mediated adipocyte loss in autoimmune lipodystrophy. $J$ Clin Endocrinol Metab. 2006;91(3):1129-1135.

126. Corvillo F, Akinci B. An overview of lipodystrophy and the role of the complement system. Mol Immunol. 2019;112:223-232.

127. Oliveira J, et al. Barraquer-Simons syndrome: a rare form of acquired lipodystrophy. BMC Res Notes. 2016;9:175.

128. Misra A, et al. Clinical features and metabolic and autoimmune derangements in acquired partial lipodystrophy: report of 35 cases and review of the literature. Medicine (Baltimore). 2004;83(1):18-34.

129. Garg A. Lipodystrophies. Am J Med. 2000;108(2):143-152.

130. Mantzoros CS, Flier JS. Insulin resistance: the clinical spectrum. Adv Endocrinol Metab. 1995;6:193-232.

131. Chen D, et al. Clinical review 153: Lipodystrophy in human immunodeficiency virusinfected patients. JClin Endocrinol Metab. 2002;87(11):4845-4856.

132. Mallewa JE, et al. HIV-associated lipodystrophy: a review of underlying mechanisms and therapeutic options. JAntimicrob Chemother. 2008;62(4):648-660.

133. Caron M, et al. The HIV protease inhibitor indinavir impairs sterol regulatory element-binding protein-1 intranuclear localization, inhibits preadipocyte differentiation, and induces insulin resistance. Diabetes. 2001;50(6):1378-1388.

134. Dowell P, et al. Suppression of preadipocyte 
differentiation and promotion of adipocyte death by HIV protease inhibitors. J Biol Chem. 2000;275(52):41325-41332.

135. Shlay JC, et al. The effect of individual antiretroviral drugs on body composition in HIV-infected persons initiating highly active antiretroviral therapy. J Acquir Immune Defic Syndr. 2009;51(3):298-304.

136. Bastard JP, et al. Association between altered expression of adipogenic factor SREBP1 in lipoatrophic adipose tissue from HIV-1-infected patients and abnormal adipocyte differentiation and insulin resistance. Lancet. 2002;359(9311):1026-1031.

137. Shrivastav S, et al. Human immunodeficiency virus (HIV)-1 viral protein R suppresses transcriptional activity of peroxisome proliferator-activated receptor $\gamma$ and inhibits adipocyte differentiation: implications for HIV-associated lipodystrophy. Mol Endocrinol. 2008;22(2):234-247.

138. Ranade K, et al. Genetic analysis implicates resistin in HIV lipodystrophy. AIDS. 2008;22(13):1561-1568.

139. Castilhos JK, et al. Polymorphisms in adiponectin receptor genes are associated with lipodystrophy-related phenotypes in HIV-infected patients receiving antiretroviral therapy. HIV Med. 2015;16(8):494-501.

140. Sweeney LL, et al. The role of adipokines in relation to HIV lipodystrophy. AIDS. 2007;21(8):895-904.

141. Nagy GS, et al. Human immunodeficiency virus type 1-related lipoatrophy and lipohypertrophy are associated with serum concentrations of leptin. Clin Infect Dis. 2003;36(6):795-802.

142.Srinivasa S, Grinspoon SK. Metabolic and body composition effects of newer antiretrovirals in HIV-infected patients. Eur J Endocrinol. 2014;170(5):R185-R202.

143. Depairon M, et al. Premature atherosclerosis in HIV-infected individuals-focus on protease inhibitor therapy. AIDS. 2001;15(3):329-334.

144.Seminari E, et al. Assessment of atherosclerosis using carotid ultrasonography in a cohort of HIV-positive patients treated with protease inhibitors. Atherosclerosis. 2002;162(2):433-438.

145. Soudan B, et al. Extreme subcutaneous insulin resistance: a misunderstood syndrome. Diabetes Metab. 2003;29(5):539-546.

146.Agarwal S, et al. Use of inhaled insulin in a patient with subcutaneous insulin resistance syndrome: a rare condition. AACE Clin Case Rep. 2019;5(3):e187-e191.

147. Jassam N, et al. Analytical and clinical challenges in a patient with concurrent type 1 diabetes, subcutaneous insulin resistance and insulin autoimmune syndrome. Endocrinol Diabetes Metab Case Rep. 2014;2014:130086.

148. Magkos F, et al. Management of the metabolic syndrome and type 2 diabetes through lifestyle modification. Annu Rev Nutr. 2009;29:223-256.

149. Grundy SM, et al. Diagnosis and management of the metabolic syndrome: an American Heart Association/National Heart, Lung, and Blood Institute Scientific Statement. Circulation. 2005;112(17):2735-2752.

150. Lloyd-Jones DM, et al. Consistently stable or decreased body mass index in young adulthood and longitudinal changes in metabolic syndrome components: the Coronary Artery Risk Development in Young Adults Study. Circulation. 2007;115(8):1004-1011.

151. Esposito K, et al. Effect of a Mediterranean-style diet on endothelial dysfunction and markers of vascular inflammation in the metabolic syndrome: a randomized trial. JAMA. 2004;292(12):1440-1446.

152. Papadaki A, et al. The effect of the Mediterranean diet on metabolic health: a systematic review and meta-analysis of controlled trials in adults. Nutrients. 2020;12(11):3342.

153. Papendieck L, Araujo MB. Clinical outcome in a series of pediatric patients with congenital generalized lipodystrophies treated with dietary therapy. J Pediatr Endocrinol Metab. 2018;31(1):77-83.

154. Lindegaard B, et al. The effect of strength and endurance training on insulin sensitivity and fat distribution in human immunodeficiency virus-infected patients with lipodystrophy. J Clin Endocrinol Metab. 2008;93(10):3860-3869.

155. Akinci G, et al. Spectrum of clinical manifestations in two young Turkish patients with congenital generalized lipodystrophy type 4. Eur JMed Genet. 2016;59(6-7):320-324.

156. Moore MM, et al. Treatment of diabetic ketoacidosis with intravenous U-500 insulin in a patient with Rabson-Mendenhall syndrome: a case report. J Pharm Pract. 2017;30(4):468-475.

157. Semple RK, et al. What is the best management strategy for patients with severe insulin resistance? Clin Endocrinol (Oxf). 2010;73(3):286-290.

158. Lane WS, et al. High-dose insulin therapy: is it time for U-500 insulin? Endocr Pract. 2009;15(1):71-79.

159. Lamos EM, et al. Concentrated insulins: the new basal insulins. Ther Clin Risk Manag. 2016;12:389-400.

160.Plamper M, et al. Mecasermin in insulin receptor-related severe insulin resistance syndromes: case report and review of the literature. Int J Mol Sci. 2018;19(5):1268.

161. Kawashima Y, et al. Leprechaunism (Donohue syndrome): a case bearing novel compound heterozygous mutations in the insulin receptor gene. Endocr J. 2013;60(1):107-112.

162. Weber DR, et al. Continuous subcutaneous IGF-1 therapy via insulin pump in a patient with Donohue syndrome. J Pediatr Endocrinol Metab. 2014;27(11-12):1237-1241.

163.LeRoith D, Yakar S. Mechanisms of disease: metabolic effects of growth hormone and insulin-like growth factor 1. Nat Clin Pract Endocrinol Metab. 2007;3(3):302-310.

164. Kohli R, et al. A randomized placebo-controlled trial of metformin for the treatment of HIV lipodystrophy. HIV Med. 2007;8(7):420-426.

165. Agostini M, et al. A pharmacogenetic approach to the treatment of patients with PPARG mutations. Diabetes. 2018;67(6):1086-1092.

166. Moreau F, et al. Efficacy of pioglitazone in familial partial lipodystrophy of the Dunnigan type: a case report. Diabetes Metab. 2007;33(5):385-389.

167. Caldwell SH. Efficacy and safety of troglitazone for lipodystrophy syndromes. Ann Intern Med.
2001;134(10):1008.

168. Simha V, Garg A. Inherited lipodystrophies and hypertriglyceridemia. Curr Opin Lipidol. 2009;20(4):300-308.

169.Shah AS, Wilson DP. Primary hypertriglyceridemia in children and adolescents. J Clin Lipidol. 2015;9(5 suppl):S20-S28

170.Ray KK, et al. Two phase 3 trials of inclisiran in patients with elevated LDL cholesterol. $N$ Engl J Med.2020;382(16):1507-1519.

171. Ray KK, et al. Safety and efficacy of bempedoic acid to reduce LDL cholesterol. $N$ Engl J Med. 2019;380(11):1022-1032.

172. Witztum JL, et al. Volanesorsen and triglyceride levels in familial chylomicronemia syndrome. $N$ Engl JMed. 2019;381(6):531-542.

173. Fogacci F, et al. Efficacy and safety of volanesorsen (ISIS 304801): the evidence from phase 2 and 3 clinical trials. Curr Atheroscler Rep. 2020;22(5):18.

174. The BROADEN study: a study of volanesorsen (formerly ISIS-APOCIIIRx) in patients with familial partial lipodystrophy. NCT02527343. Updated January 10, 2020. Accessed January 11, 2021.

175. Ahmad Z, et al. Inhibition of angiopoietin-like protein 3 with a monoclonal antibody reduces triglycerides in hypertriglyceridemia. Circulation. 2019;140(6):470-486.

176. Graham MJ, et al. Cardiovascular and metabolic effects of ANGPTL3 antisense oligonucleotides. N Engl J Med. 2017;377(3):222-232.

177. Study of gemcabene in adults with FPLD. NCT03508687. Updated August 17, 2020 Accessed December 25, 2020.

178. US Food and Drug Administration. Highlights of prescribing information. https:// www.accessdata.fda.gov/drugsatfda_docs/ label/2014/125390s000lbl.pdf. February 2014. Accessed December 13, 2020.

179. Chan JL, et al. Clinical effects of long-term metreleptin treatment in patients with lipodystrophy. Endocr Pract. 2011;17(6):922-932.

180. Oral EA, et al. Leptin-replacement therapy for lipodystrophy. NEngl JMed.2002;346(8):570-578.

181. Zadeh ES, et al. The liver diseases of lipodystrophy: the long-term effect of leptin treatment. JHepatol. 2013;59(1):131-137.

182. Petersen KF, et al. Leptin reverses insulin resistance and hepatic steatosis in patients with severe lipodystrophy. J Clin Invest. 2002;109(10):1345-1350.

183. Simha V, et al. Comparison of efficacy and safety of leptin replacement therapy in moderately and severely hypoleptinemic patients with familia partial lipodystrophy of the Dunnigan variety. JClin Endocrinol Metab. 2012;97(3):785-792.

184.Brown RJ, et al. Effects of metreleptin in pediatric patients with lipodystrophy. JClin Endocrinol Metab. 2017;102(5):1511-1519.

185. Chan JL, et al. Immunogenicity associated with metreleptin treatment in patients with obesity or lipodystrophy. Clin Endocrinol (Oxf) 2016;85(1):137-149.

186. Brown RJ, et al. Lymphoma in acquired generalized lipodystrophy. Leuk Lymphoma. 2016;57(1):45-50.

187. Falutz J, et al. Metabolic effects of a growth hormone-releasing factor in patients with HIV. 
N Engl J Med. 2007;357(23):2359-2370.

188. Lo J, et al. Low-dose physiological growth hormone in patients with HIV and abdominal fat accumulation: a randomized controlled trial. JAMA. 2008;300(5):509-519.

189. Falutz J, et al. A placebo-controlled, dose-ranging study of a growth hormone releasing factor in HIV-infected patients with abdominal fat accumulation. AIDS. 2005;19(12):1279-1287.

190.Falutz J, et al. Effects of tesamorelin, a growth hormone-releasing factor, in HIV-infected patients with abdominal fat accumulation: a randomized placebo-controlled trial with a safety extension. J Acquir Immune Defic Syndr. 2010;53(3):311-322.

191. Falutz J, et al. Effects of tesamorelin (TH9507), a growth hormone-releasing factor analog, in human immunodeficiency virus-infected patients with excess abdominal fat: a pooled analysis of two multicenter, double-blind placebo-controlled phase 3 trials with safety extension data. JClin Endocrinol Metab. 2010;95(9):4291-4304.

192.Iseri K, et al. Rituximab for the treatment of type $B$ insulin resistance syndrome: a case report and review of the literature. Diabet Med. 2017;34(12):1788-1791.

193. Viswanathan L, Sirisena I. Immunosuppressive therapy in treatment of refractory hypoglycemia in type B insulin resistance: a case report. JEndocr Soc. 2017;1(12):1435-1439. 